This item was submitted to Loughborough's Research Repository by the author.

Items in Figshare are protected by copyright, with all rights reserved, unless otherwise indicated.

\title{
Art therapy techniques as a novel creative method for exploring design for home happiness
}

PLEASE CITE THE PUBLISHED VERSION

https://doi.org/10.1504/JDR.2018.099533

\section{PUBLISHER}

(c) Inderscience Enterprises Ltd.

\section{VERSION}

AM (Accepted Manuscript)

\section{PUBLISHER STATEMENT}

This paper was accepted for publication in the journal Journal of Design Research and the definitive published version is available at https://doi.org/10.1504/JDR.2018.099533.

\section{LICENCE}

CC BY-NC-ND 4.0

\section{REPOSITORY RECORD}

Corrigan-Kavanagh, Emily, and Carolina Escobar-Tello. 2019. "Art Therapy Techniques as a Novel Creative Method for Exploring Design for Home Happiness". Loughborough University.

https://hdl.handle.net/2134/37753. 


\section{Emily Corrigan-Kavanagh}

e.corrigandoyle@surrey.ac.uk,

University of Surrey, Guildford, UK

With a background in Visual Communication and Critical Design Practice, Emily is currently the Research Fellow in Communication Design on the Next Generation Paper Project at University of Surrey where she is exploring the design aspect of how ordinary paper can be connected to the web. Prior to this, she completed her $\mathrm{PhD}$ at Loughborough University where she pioneered the application of art therapy techniques in a design context to investigate design for happier homes. Emily has published in journals and books, presented papers at conferences nationally and internationally and has also won multiple awards for her academic activities. Her research interests include designing for augmented paper, home, creative research methods, and design for happiness and wellbeing.

\section{Carolina Escobar-Tello}

C.Escobar-Tello@lboro.ac.uk

Loughborough University, Loughborough, UK

Carolina is a progressive researcher, designer, and facilitator working across industrial, service, and systems design. Currently a Lecturer in Design at Loughborough Design School, Loughborough University. With extensive professional multicultural design and management experience in the industrial, non-for-profit, and governmental arena (UK; USA; Europe; South America), her work has been published in journals and international peer-reviewed conference proceedings. She is an expert in Design for Happiness, Sustainable Design \& Social innovation, and co-convenor of the Design Research Society Special Interest Group on Sustainability; and the Design Research Society Special Interest Group on Design for Health, Wellbeing and Happiness. 


\title{
Art therapy techniques as a novel creative method for exploring design for home happiness
}

\author{
Home can play a central role in influencing societal practices, being, among other \\ conceptualisations, a social system supportive of basic and psychological needs. \\ Art therapy techniques can be used for exploring home happiness from this \\ perspective. They appear to enable the identification of systemic facilitators of \\ happy home moments, informing design opportunities. This paper discusses art \\ therapy techniques as a new tailored creative method for exploring this within \\ design research. It begins by describing relevant home and happiness concepts, \\ art therapy techniques and similar creative methods. This is followed by an \\ explanation of how art therapy approaches were used to examine practices for \\ home happiness. Subsequently, research results are highlighted, such as how \\ 'design for home happiness' can create applicable design products and services. \\ Finally, implications of employing art therapy techniques in 'designing for home \\ happiness' are suggested.
}

Keywords: art therapy techniques; design tools; research methods; home; designing for home happiness; creative methods

\section{Introduction}

The home can be understood as a platform for self-expression (De Botton, 2006; Cristoforetti, Gennai and Rodeschini, 2011) as well as a material place, providing shelter and warmth. Accordingly, it can facilitate activities for both basic and psychological needs, enabling happier lifestyles. This paper focuses on the subjective aspects of the material home from a happiness perspective by considering interactions between individuals and related objects and/or environments that holistically contribute 
to home happiness and prominently how art therapy techniques can be used to examine it.

Composed of interweaving practices between people, artefacts and social cues (Ingold, 2011), home is a complex system. Designing for happier homes therefore requires firstly exploring home happiness systemically to understand how designed products and services could possibly support it. Creative methods — defined here as those that involve participants creating something through photography or artwork—are a useful strategy to do this. Activities where individuals generate related artefacts, commonly employed in generative research (Visser et al., 2005), have been suggested to elicit feelings that are problematic to describe, through collage making (Hanington, 2007) and art making for example (Corrigan-Kavanagh, 2018), and motivate truthful responses by discussing resulting artwork and photography (ibid).

Moreover, the ability of art making to activate corresponding areas of the brain for associated emotions being depicted has been illustrated in Art Therapy through research employing MRI (Magnetic Resonance Imaging) brain scans (Lusebrink and Alto, 2004). In the same way that creative methods allow for the exploration of subjective experiences of users, art therapy techniques could be used as an alternative approach in design research for this purpose. This paper therefore focuses on presenting art therapy techniques as an original method for exploring subjective experiences in this area. It discusses the outcomes of investigating how art therapy techniques could be used for 'designing for home happiness', and how the results of this could inform future design projects, such as for products and service designs.

It begins by describing how home is made, happiness and its relationship to home, and the suitability of art therapy techniques for investigating home happiness. Succeeding this, a comparison of art therapy techniques to similar creative methods is 
provided, followed by an elaboration of how art therapy techniques were applied for this research. Lastly, findings are presented, such as how designed services and products could be used to support home happiness. Conclusions discuss future implications of utilising art therapy techniques as a creative design research method.

\section{The creation of home}

Home, is produced by interweaving practices between people and objects (Ingold, 2011), can provide a reflection of oneself and its reconfiguration enables evolutions of identity (Cooper, 1974). Correspondingly, home manipulations can motivate interactions that take place and how individuals think and feel in them (Gosling, Gifford and McCunn, 2013). For example, a room's physical layout and furniture can motivate food preparation (i.e. kitchen arrangement) or sleeping/relaxation (i.e. bedroom configuration). Artefacts of personal meaning, such as family photos, can encourage emotions of intimacy with others (Gifford, 2007) and time together in the home sharing resources, such as food and electricity. Certain home facilities, such as microwaves and televisions, provide convenient avenues to satisfying basic needs. Thus, home can support various interactions that can contribute to happiness - or the reverse by the same mechanisms. Highlighting 'home' as an evolving and influential context through the affordances of its space and contained artefacts therefore present it as an opportunistic place to create happier lifestyles through design.

\section{Happiness and its importance in the home}

Happiness is difficult to define as its conceptualisation and conditions vary with everyone. However, Martin Seligman (2002), a pioneer of positive psychology—a branch of psychology that presents strategies for mental wellbeing instead of curing 
illbeing, conductive to investigations for 'design for home happiness' - shows that longterm happiness or 'authentic happiness' can be divided into three sequential levels and supported through their associated activities, customisable to varying individuals. These include The Pleasant Life, The Good Life, and The Meaningful Life. The Pleasant Life encompasses happiness as fleeting pleasure, usually resulting from physiological needs being satisfied such as food, and bursts of positive emotion (i.e. joy and love) through external stimulus (i.e. viewing a beautiful painting). The Good Life depicts happiness as engagement in actions that employ and/or advance one's strengths (i.e. kindness, bravery) (Peterson and Seligman, 2004), fulfilling psychological needs. Lastly, The Meaningful Life refers to happiness as meaning, where one's strengths are employed for others, such as a charity, also supporting psychological needs. This research therefore classifies 'happiness' as a collective experience of pleasure (The Pleasant Life), engagement (The Good Life) and meaning (The Meaningful Life).

Many current designs for home, such as commercial products, tend to most overtly support pleasure by satisfying basic needs - for example through provision of adjustable lighting and microwaves to accommodate resting and eating. Furthermore, of those that could support additional components of happiness, such as engagement and meaning - a writing desk (engagement) or cooker for preparing a meal for a loved one (meaning) — related actions need to be self-motivated; they are not necessary to survival and therefore can be neglected in unhappy homes, unlike satisfying basic needs (The Pleasant Life). For example, if an individual was experiencing a depression in his/her life, s/he will most likely lack motivation or find it nearly impossible to engage in his/her hobbies (i.e. writing) or in acts of kindness for loved ones (i.e. preparing food/drink for others). However, s/he will be biologically forced to use these products to fulfil basic needs, at least eventually, to continue living. Even when engaging in these 
activities, s/he may not be fully present in the moment, preoccupied by issues that are having a negative impact on his/her wellbeing and so less able to experience engagement and meaning from them. Notably, meaning is used here to denote Seligman's Meaningful Life. It does not refer to the capacity of products to act as signifiers of desirable qualities (i.e. playful, sophisticated) that evoke positive user experiences (Norman, 2004) (i.e. of luxury or attachment) (Desmet and Hekkert, 2007) — Tiffany lamps for example denote naturalistic ornamentations with high quality materials, appealing to aspiring high-class nature lovers.

Additionally, though influential in supporting pleasant home experiences, ornamental home products tend to emphasise individual self-meaning as opposed to group interaction. Although these pieces could add to creating a warm atmosphere for positive group interactions of pleasure, engagement and meaning, they are still reliant on the quality of the relationships between individuals to have this effect and will not necessarily initiate interaction. If inhabitants had negative connections with each other and/or were struggling with emotional difficulties, it is conceivable that decorative household objects would unlikely be enough to support a home context for pleasure, engagement and meaning collectively. This is significant as previous research illustrates that positive experiences with others in the home has the greatest potential to satisfy most home happiness needs (Corrigan-Doyle, C. Escobar-Tello and Lo, 2016a). There are thus opportunities for designed products or services that purposefully support positive experiences with others to improve happiness and sustainability in the home.

\section{Art therapy techniques as methods for exploring home happiness}

Art Therapy - a type of psychotherapy that uses art making to treat physiological and mental disorders or aid in self-development (Malchiodi, 2007) — uses art making with 
specialised techniques to highlight inner thoughts and feelings and induce positive affect (Drake, Coleman and Winner, 2011). These have been previously utilised in other research contexts such as sociology (Deacon, 2006; Gauntlett and Holzwarth, 2006; Awan, 2007) but appear absent from previous design related discourses.

Moreover, prior research into home surroundings, components and/or interactions has mostly come from technological, anthropological or built environment perspectives where certain happiness aspects are neglected (Affinity Sutton, 2011; Anastaselos et al., 2016) or not the primary focus (Cieraad, 2006; LEEDR (Low Effort Energy Demand Reduction) project, 2014; Pink, Leder Mackley and Morosanu, 2015). Taking these viewpoints does not encompass home happiness aspects comprehensively. Examining home through an 'authentic happiness' lens requires exploring all home interactions for pleasure, engagement and meaning —or absence of —including technology, built environment and social aspects that influence these, to comprehend how home happiness can be supported. Being historically utilised for illuminating an individual's subjective experience, art therapy techniques present a means of examining home from this perspective.

\section{A comparison of art therapy techniques to similar creative methods}

Creative methods support the design process by either providing inspiration, information or new understandings about relevant contexts for design ideas. Art therapy techniques might complement current creative methods in understanding subjective experiences and designing for relevant services, products or systems by taking an alternative approach. There are numerous creative methods employed in design research. For succinctness of argument, this section focuses on probes and generative toolkits as they bear the greatest similarity to art therapy techniques but are nonetheless 
different. Although art-based research, which extends beyond design, can employ artmaking among other arts-based activities (i.e. creative writing, music) to explore different contexts (McNiff, 2008) it arguably doesn't include a series of art therapy-like techniques (i.e. silent and spontaneous artmaking followed by open reflection) employed collectively - explained in subsequent sections - to stimulate deep reflection during tasks. Specifically within design research, probes and toolkits are selected for discussion as they both can involve sensitisation exercises, artmaking and open reflection — also present in art therapy techniques — to intentionally explore feelings around topics within design research. Art making activities are called projective techniques in this context, used to investigate thoughts and feelings difficult to verbalise around particular topics (Hanington, 2007). Examples include collage making-sticking together fragments of found imagery, textures and scrap paper to portray an image, mood or concepts - and concept mapping - mapping out an ideal experience with materials including different shapes of coloured card, word stickers and symbols to portray real world objects and feelings (Butler-Kisber and Poldma, 2010).

Probes invite participants to share their feelings and experiences in creative formats, predefined and created by experts (i.e. designers), the results of which can be used selectively (Sanders and Stappers, 2014b). They are reliant on active participation from individuals to complete exercises unobserved (Mattelmäki, 2006). Notably, the accuracy of probe responses are questionable in exploring in-situ subjective experiences; it is difficult to have participants complete tasks in action-based scenarios, which limit answers to retrospective reflections (Hulkko et al., 2004). Additionally, it is hard to decipher if participants were emotionally engaged while completing activities as these are conducted away from the researcher. 
On the other hand, most art therapy techniques — such as silent art making in a group on a particular topic (i.e. home) followed by each individual explaining their image - are used in the presence of a facilitator to create a context for deep emotional reflection. In this manner, the environment for art creation is a lot more controlled to deliver insightful explanations of events from participants. Art therapy techniques could hence be used as a subsequent method for investigating the reliability of probe results more intensely or the probe method could be used as a sensitisation activity for the later use of art therapy techniques.

Toolkits are personalised/designed by researchers and/or designers towards each project's aims (ibid) and can include individuals creating collages, concept maps with cut out words and shapes or drawing and painting (Sanders and Stappers, 2012). They are participatory/codesign methods that are generally employed to support collective creativity and collaborative ideation amongst stakeholders and designers (Sanders, 2001, 2006), generating culturally sensitive designs (Sanders and Stappers, 2012). Accordingly, materials for projective tasks within these are usually orchestrated with pre-prepared images and words to allow all participants to create compositions rapidly together (ibid). Consequentially, deep individual emotional exploration is not the priority, and group work and conversation is encouraged to reach collective understandings around relevant issues.

In contrast, art therapy techniques focus on individual expression and reflection (Malchiodi, 2007). Throughout Art Therapy-led sessions, spontaneous art making employing unstructured materials, such as paints, brushes and paper, can be utilised to support the emergence of individuals 'internal worlds'(Rubin, 2001). Art making is generally conducted in silence to facilitate this (Silverstone, 2009). Furthermore, after art creation participants are encouraged to openly reflect about their artwork 
individually without interruption from group members - the meaning of each participants' art in this context is understood to only be known by them (Malchiodi, 2007) and should not be interpreted by others. Through this, art therapy techniques collectively by-pass defensive thinking and persuade free self-expression (ibid). They hence provide an alternative means of exploring individual subjective experiences that could be used in conjunction with toolkits. For example, art therapy techniques could be employed to identify facilitators of positive experiences in different contexts and toolkits could be used to investigate results further and prototype design solutions with different stakeholders. Another approach could be to employ toolkits initially and then use art therapy techniques to more deeply explore findings, such as feelings or experiences within certain contexts. Further discussion of this is beyond the scope of this paper.

\section{Methodology for investigating home happiness using art techniques}

Art therapy techniques were identified as a viable approach for examining home happiness, especially positive experiences with others in the home, specifically family. Prior research identified positive family experiences as those that could satisfy multiple home happiness needs simultaneously (Corrigan-Doyle, Escobar-Tello and Lo, 2016a). The term 'family' is used broadly here to refer to strong social relationships including close friendships. Applicable art therapy techniques to support a workshop process for in-depth personal explorations of positive family experiences were also identified and verified through consultation with an art therapy expert — this individual had a $\mathrm{PhD}$ in Art Therapy and 12 years of practitioner experience. Art therapy techniques included those for encouraging sensitisation to significant home happiness aspects prior to the workshop, an ice breaker activity to allow participants to feel at ease about the 
workshop's expectations, an introductory art making exercise exploring home happiness to help individuals get used to materials followed by a final one examining positive family experiences extensively.

A bespoke workshop format (Happy-Home Workshops) for investigating these experiences, utilising suitable art therapy techniques, was therefore trialed through a pilot (Corrigan-Doyle, Escobar-Tello and Lo, 2016b), and, upon its success, employed in two studies - the focus of this paper. Each study consisted of a two-hour group workshop with follow-up individual semi-structured interviews of around half an hour duration to explore workshop results, held at Loughborough University.

Participants sample consisted of professional middle-class UK families living in the town of Loughborough and were recruited through advertisement posters. Participants were notified of the use of art therapy techniques in workshops through these advertisements and it was stressed that the sessions did not involve therapy. The focus of the workshop was also kept positive (i.e. happy home experiences) to limit any negative emotions being triggered by activities. Subsequent sections describe the process followed, including art therapy techniques employed and rationales.

\section{Creating a suitable workshop scenario for exploring home happiness}

Careful considerations were given to ensure a suitable workshop structure, including appropriate venue, and number and type of participants. The quantity of individuals for each workshop was purposefully kept small to allow each person sufficient time for individual open reflection in the group and to create a more intimate and supportive atmosphere for this (Liebmann, 2004, p. 32). The first study recruited five participants, and the second obtained six. Participants were sought using criterion sampling; adult (over 18 years) and currently living with family or a partner. Exploring positive family 
experiences required recruiting participants that were presently having 'family experiences' regularly, such as daily or weekly. Notably, 'families of choice' cohabiting arrangements also exist (Duncan and Phillips, 2008) where family-like connections are exhibited in long-term friendships. Demanding proper investigation to distinguish these relationships from those more casual, this group was deliberately omitted from sampling criteria for time efficiency throughout recruitment.

The workshops were divided into three sequential activities: Activity 1, Personal Art History and Image Awareness Exercise; Activity 2, Spontaneous Art Making Exercise; Activity 3, Visualising Positive Family Time Exercise. These activities were conducted individually by participants and at the end of each art making task they shared their results with the rest of the group. Table 1 offers a summary of activities.

The Personal Art History Exercise during Activity 1 was employed to eliminate false expectations of art-making tasks, negative connotations of materials, paints or brushes for example. The Image Awareness Exercise (Activity 1) allowed participants to become aware of each other's commonalities, such as home aesthetics, while increasing awareness of meaningful home features. Furthermore, this was employed to assist in reflections of later resulting artworks and, collectively, Activity 1 tasks (Personal Art History and Image Awareness Exercises) acted as an icebreaker. By initiating the workshop in this manner, participants could use preparation materials (i.e. imagery from one's home or recollections of personal experiences with art) to introduce themselves and relay any issues or concerns they harboured towards the workshop's expectations before art making activities commenced. This set an inviting atmosphere among the group for later art expression and individual explanations of outcomes.

Activity 2 provided participants with an opportunity to explore the large assortment of art materials available and begin visualising thoughts from previous 
reflections. This varied selection also offered them additional liberty in art composition — to visualise 'their authentic selves' (Rubin, 2011). Moreover, conducting art making in a sporadic manner on a page with a visual prompter (i.e. outline of house) encouraged free associations of home definitions. Subsequently, explaining their image individually to the group encouraged collective learning as these open reflections could evoke revelations for others about their own imagery (Liebmann, 2004). Consequently, Activity 1 and 2 sensitised participants to personal home associations and related feelings. For example, the Image Awareness Exercise in Activity 1 encouraged individuals to become more visually aware of significant imagery in their home and Activity 2 motivated their initial visualisation through illustrative prompts and spontaneous art making. Activity 3 focused participants' attention specifically on positive family time by asking individuals to create depictions of this. Notably, all art making tasks (Activity 2 and 3 ) were conducted in silence to improve concentration and reduced contamination from others as 'talking can shatter the image' (Silverstone, 2009).

Related elaborations were examined more closely in follow-up one-to-one semistructured interviews occurring a few days after workshops. This accommodated a more private space for more open and deep answers. It also provided participants with time away from their artworks. This is particularly significant from an art therapy perspective; returning to an image after a period of time can lead to new understandings of its meaning (Malchiodi, 2007, p. 60). Interview schedules were specified to each participant's use of colour, materials, placement and size of relevant figures, including questions such as 'Why did you use paint?'. These were also accompanied by some generic questions, for example 'What does it mean to be happy in this scenario?'-all with the aim of instigating further reflection on home happiness. 


\section{Making sense of Workshops' findings}

Following the completion of the workshops and accompanying individual semistructured interviews, data collected included video/audio recordings and field notes of workshop activities, 22 artworks, and aural content from 11 semi-structured interviews - averaging at 29 minutes and 58 seconds. Permission for using audio/video recording during the workshop and sound capture in the interviews was gathered prior to each session using an informed consent form; each participant was asked to read and sign this if they agreed with the terms. Figure 1 offers a sample of artworks.

Notably, personal biases built from previous experiences can be projected onto another's artwork when trying to decipher it (Malchiodi, 2007). For this reason, analysis of resulting content was restricted to each participant's renditions of his/her compositions' meaning, provided during the workshops and semi-structured interviews. Accordingly, full transcriptions of workshop and semi-structured interview audio were created to analyse emerging themes around positive family experiences.

Using a grounded theory approach, this was undertaken using sensitising questions (i.e. what supports this moment? How and why is this true?) and open coding (Corbin and Strauss, 2008). Analysis was conducted manually both on and off screen on typed up transcription documents — codes were individually highlighted using colour coding and comments boxes in Microsoft Word. After establishing initial categories and possible properties, the constant comparison technique was employed to axial code the data - to draw connections between themes and codes (ibid). The full list of emerging themes and codes can be viewed in Table 2 with sample extracts from semi-structured interview and workshop individual responses. The codes represent the components/facilitators of positive family experiences and the themes illustrate how 
they are expressed in this context, such as by either being emotionally felt, or physically enacted by individuals involved in the experience. These will be explained in detail in subsequent sections. An initial theory was then conceptualised through extensive theoretical memoing involving these themes and codes. This was tested by considering a conditional matrix (ibid) for positive family time, principally how it is conceived and affected at the individual and collective/group/family level — such as how positive family experiences support the happiness of specific individuals and the household concurrently.

\section{Results and discussion}

Overall findings from these studies provided evidence of the suitability of art therapy techniques for exploring home happiness, as well as revealing facilitators of positive family experiences in this context. The succeeding sections provide the highlights from these findings and suggest valuable implications for utilising art therapy techniques as a creative method in design research.

\section{Value of using art therapy techniques for exploring home happiness}

Collectively, art therapy techniques appeared to create a suitable social context for deep personal reflection. Sharing previous experiences through art and important elements of their home (Activity 1) allowed participants to draw connections between each other's experiences and home life_ - acknowledging this through comments such as, 'We're all in the same boat'-facilitating a welcoming space for emotional expression. Furthermore, workshop activities stimulated participants' reflections about the significant aspects of their home experiences and surroundings (i.e. facilitators of 
happiness), triggering descriptions of feelings instead of thoughts—-for example, 'You feel a sensation of security, warmth [when] the people most important to you are safe'.

Activity 2 (Spontaneous Art Making) allowed participants to start

visualising/free associating meaningful themes that were mentioned in Activity 1, such as insights around home life. Additionally, illustrating positive family experiences in Activity 3 appeared to improve participants' mood as this confirmed positive aspects of home - evidenced by interview responses including, 'It made me think I have a positive family experience with my family every day' and 'It was the nicest thing I did that day'.

Resulting artworks also served as prompts during workshop and semi-structured interview responses. Accordingly, the workshop seemed to facilitate a platform for appreciating significant home aspects while also providing an enjoyable experience. Furthermore, this positive affect appeared to motivate participant receptivity in followup semi-structured interviews; participants were very accommodating with interview dates, required very little prompting during interview discussions and most desired to extend the conversation after all questions had been answered.

\section{Designing for home happiness through positive family experiences}

Analysis of 11 positive-family-experience-recollections implied that design could theoretically support spontaneous positive family experiences most effectively by acting as objects (i.e. products) and/or contexts (i.e. services) that facilitated group activities for pleasure, engagement and meaning concurrently. In this manner, using art therapy techniques with participants seemed to enable comprehensive elaborations of their positive family experiences, which allowed for the identification of characteristics and facilitators of these experiences in later analysis. The main findings are illustrated in Table 3 and discussed in detail in following sections. 


\section{Characteristics of positive family experiences}

Analysis of participants' descriptions of positive family experiences suggests that positive family experiences are composed of characteristics that are physically enacted - they demand some action from participants - and emotionally felt - they are naturally experienced during these moments without conscious action. These terms formed the two themes for all emerging codes that were representative of positive family experience supporters. Under the theme physical enacted characteristics corresponding codes/facilitators included: together, synchronised rest periods (i.e. making time for each other either consciously or unconsciously), objects and/or contexts that facilitating collective interaction, and group activities - as illustrated in Table 2 with exemplary quotes. For example, participants appeared to need to be together (together), create time for each other (synchronised rest periods), prepare environments that supported positive interactions (i.e. a comfortable communal space) (objects and/or contexts that facilitating collective interaction) and engage in collective activities (i.e. playing a game) (group activities) in order to experience a positive family experience.

Codes/facilitators of positive family experiences within the emotionally felt characteristics category were feeling: socially relaxed, supported, togetherness, and [that] time doesn't matter, also displayed in Table 2 with example responses. For instance, all participants reported spending large periods of time with family during these experiences because they felt that time didn't matter. Additionally, they were very socially relaxed (e.g. 'There's not so much that needs to be said... you can sit in silence') and felt emotionally (e.g. 'We always talk about our problems') and physically (e.g. 'I need to ensure that everyone is fed') supported through interactions such as eating and talking with family. Furthermore, results suggest that being physically 
together could lead to feelings of emotional togetherness built from previous positive social interactions with family members (e.g. 'It's nice to prepare food together... when we do we really enjoy it').

In this manner, physically enacted characteristics appear to evoke emotionally felt qualities of positive family experiences. For instance, synchronised rest periods could allow for notions that time doesn't matter, exemplified by responses such as, 'We're all so busy. [Celebrating birthdays is] a nice time to come together... everyone has time for each other'. Objects and//or contexts that facilitated collective interaction, could also encourage a socially relaxed environment by visually accommodating interactions from multiple individuals simultaneously_one example included a participant's living room that had all the furniture repositioned in preparation for a family dinner and film night. It therefore appears possible to motivate positive family moments if physically enacted characteristics (i.e. together, synchronised rest periods, objects and/or contexts that facilitate collective interaction, group activities) are actioned by family members.

\section{Physical and emotional binders within physically enacted characteristics}

Findings imply that positive family experiences involve (physically enacted) group activities together that emotionally bind individuals to the experience. Exemplary responses included, 'I have feelings of great closeness to my sisters... I do feel part of something'. Accordingly, these are named emotional binders and could include eating, drinking, resting (pleasure) and/or playing, learning and talking together (engagement), and caring for the household (meaning). Additionally, evidence suggests that emotional binders are supported by objects and/or contexts that physically bind family members to or facilitate their involvement in a collective experience—called physical binders. 
These include comfortable communal spaces (i.e. living room) and furniture (i.e. couches), food, drink, television, craft materials and board games. For example, one participant's positive family experience involved the whole family having 'Sunday lunch' together; the dining room, table, chairs and food were all the physical binders and the corresponding activities, talking and eating, were the emotional binders as these activities positively engaged the family in that experience. The relationships between physically and emotionally enacted characteristics, and how they lead to positive family experiences are visually illustrated in Figure 2 using these classifications.

\section{How positive family experiences can support long-term home happiness}

Evidence suggests that positive family experiences can include all components for longterm happiness through their emotional binders, such as through group activities for pleasure (i.e. resting together), engagement (i.e. making something with others) and meaning (i.e. helping the family) during these moments. Consequently, emotional binders can be divided into those that facilitate basic needs - emotional binders for pleasure - and those that support psychological needs-emotional binders for engagement and/or meaning.

\section{Types of positive family experiences}

Further analysis of positive family experiences discussed also implied that they can be categorised as spontaneous, planned, or routine - differentiated by the sequence their physically enacted characteristics occur. These classifications were not used directly by participants but were illustrated in the way they described them. For example, spontaneous pleasant home moments seem to be instigated by the physical binder(s) that encourages individuals to come together and synchronise their rest periods (i.e. 
make time for each other and/or spend a prolonged period of time together) and engage in an emotional binder (see Figure 3). A relevant moment illustrated by a participant included one that was initiated by an open fire (physical binder). The participant started a fire in the back garden that led the whole family to group (together) and stay with each other for an extended period (synchronise rest periods) to watch it (emotional binder for pleasure).

Routine family moments appear to be those with some predictability in terms of when and what happens, requiring minimal preparation. They occur when the family members are naturally together and a physical binder enables/encourages communication (emotional binder), motivating individuals to spend a significant portion of time with each other (synchronise rest periods) (see Figure 4). For instance, one participant described occasions that would take place daily generally between five and six daytime; the whole family would happen to be together in the living room (physical binder) and a game (emotional binder for engagement) would naturally develop, with a balloon (physical binder) in the example given, encouraging them to synchronise their rest periods in the moment and/or in future occasions. Importantly, this activity was not formally planned; it could also occur at different times of the day when all family members naturally gravitated in the living room together. Synchronising rest periods therefore seem to occur at the end of routine family moments as the enjoyable interaction appears to convince those involved either consciously or unconsciously to spend a prolonged period of time together. In this sense, routine positive family experiences can be theorised as ideal happy home moments because they appear to occur regularly without much prompting/planning.

Planned family experiences seem to begin by family members consciously synchronising their rest periods to allow them to come together, in which a physical 
binder supports an inclusive activity (emotional binder) (see Figure 5). An exemplary positive family experience involved a participant's family planning a time (synchronise rest periods) to be together on the couch (physical binder), in front of the television (physical binder), to relax and watch a film (emotional binder for pleasure).

\section{Implications for Designing for Home Happiness}

Results imply that spontaneous family moments can be triggered by a physical binder, activating the three remaining elements — together, synchronised rest periods and emotional binder(s) - requiring minimal planning (i.e. planned positive family experiences) or the family already being together (i.e. routine positive family experiences). A product or service could therefore potentially act as the physical binder to instigate a spontaneous positive family experience by supporting emotional binders (activities within these moments) for pleasure, engagement and meaning collectively. For instance, physical binders are defined as objects or contexts that facilitate emotional binders within positive family experiences; products could plausibly act as these objects while services could create contexts for them. An example could include a service design (physical binder) that connects (together) and facilitates meet-ups for families (synchronised rest periods) with complementary needs and skills, allowing them to socialise (emotional binder for engagement) and help (emotional binder for meaning) each other fulfil household tasks simultaneously, such as cooking and home repairs (emotional binders for pleasure).

Furthermore, findings suggest that if emerging spontaneous family moments are successful in satisfying the happiness of all family members, they could potentially evolve into a routine pleasant family experience. Understanding this, designing for spontaneous positive family moments through designs acting as physical binders- 
supportive of emotional binders for pleasure, engagement and meaning concurrentlydisplay the largest potential for improving home happiness.

\section{Research Limitations}

Important limitations to note include the studies' sample size, social class and context. 11 participants took part whom where all from professional middle class backgrounds residing in the UK. Findings are therefore primarily a reflection of this group. In order to add validation to resulting concepts, an online questionnaire consisting of one closed and two open questions based on studies' results was posted on social media (i.e.

Facebook and Twitter) to gather additional feedback from other social groups, achieving 27 responses. Although answers did qualify findings further, it was difficult to be certain that social diversity was achieved due to its anonymised nature. Its full discussion is beyond the scope of this paper, but its mention is significant to attest to the seemingly promising contribution of these findings for 'designing for home happiness'.

\section{Ethical Considerations}

Other notes worthy of discussion are the ethical implications of employing art therapy techniques within a research context. Art can be a powerful communication tool. Consequently, it can harm as well as help individuals when used within Art Therapy by surfacing painful emotions (Springham, 2008). However, it seems that with carefully workshop planning, such as centering activities on a positive topic, home happiness for example, and recruiting psychologically healthy individuals, negative participant experiences can be greatly avoided. Understanding this, participants from vulnerable groups should not be recruited when using this method unless an art therapist will be present and/or can evaluate the workshop process with the researcher beforehand to 
locate any activity that might be triggering. During these studies, these strategies were implemented by overtly stating that sessions did not involve therapy in participationcalls, with criteria that included 'over 18 years of age'. Furthermore, the facilitator's introduction to Art Therapy-Led workshops highlighted that although employing/borrowing some art therapy techniques it did not provide therapy. Moreover, contact information for Loughborough University and NHS counseling services were kept close to hand during sessions in case a participant needed a mental health intervention. Lastly, follow-up semi-structured interview questions were careful chosen for their relevance to the topic under study to remove resemblance of a therapy session. These procedures proved effective in maintaining a safe and welcoming environment for participants as all reported that they really enjoyed the workshops in the feedback forms and in subsequent interview discussions and none required emotional assistance during or after sessions.

\section{Conclusions and future work}

This research set out to examine how art therapy techniques could be used to 'design for home happiness'. Findings infer that art therapy techniques, specifically within the context of the Happy-Home Workshops discussed in this paper, present a new creative method to explore home happiness, positive family moments in particular. They encourage participants to volunteer truthful and thoughtful responses by motivating them to reflect and explain significant visual aspects of their home in Activity 1. Spontaneous art making in Activity 2, utilising a triggering visual prompt (i.e. outline of a house symbol), provides a platform to depict these contemplations after prior sensitisation from Activity 1 . Activity 3 focuses attention on composing positive family experiences, using previous tasks as warm-up exercises-for example, Activity 1 
initiates relevant thinking and Activity 2 allows for experimentation with art materials in a liberal fashion. Overall, these studies uncovered findings that illustrate how positive family experiences may act as facilitators of home happiness. By motivating activities for pleasure, engagement and meaning concurrently with others, they seem to support future positive communal interactions.

Furthermore, using art therapy techniques in this manner allowed for the theorisation of how designed products or services could facilitate positive family experiences; all are composed of four physically enacted elements (i.e. synchronised rest periods, together, emotional binders, physical binders) and design could support these by acting as the physical binder (i.e. product or service), triggering the remaining three. Future research will therefore aim to test and further verify these findings by conceptualising and trialing related 'design for home happiness' interventions. Through this, it will also explore how art therapy techniques could be employed with other creative methods, such as using toolkits to prototype outcomes with stakeholders. It would also be ideal to employ art therapy techniques to investigate experiences in different contexts, such as in healthcare, to examine their transferability and appropriateness in understanding and designing for other subjective moments in other scenarios.

Generally, the results show potential in advancing creative methods and 'designing for home happiness'. Collectively, art therapy techniques appear to present an effective means of exploring home happiness and, for this reason, could possibly be used to investigate 'design for happiness' opportunities in other areas outside of home, while taking appropriate ethical measures as previously outlined. For example, future explorations could include identifying and designing for facilitators of positive work experiences from the perspective of managers, business owners and/or general 
employees, supporting happy working contexts for all. Moreover, art therapy techniques may complement similar creative design methods (i.e. toolkits, probes) that employ related techniques (i.e. art making); they support contexts for supervised individual subjective introspection that could be used in conjunction with other methods that facilitate creative group collaborations in exploring design solutions (i.e. toolkits) or reflective exercises conducted in private (i.e. probes). Results from employing art therapy techniques could therefore guide or supplement design activities using other creative methods to conceive relevant outcomes. Through this, art therapy techniques show potential in advancing design's ability to improve happiness in the home, and experiences in other areas.

\section{References}

Affinity Sutton (2011) FutureFit report. London.

Anastaselos, D. et al. (2016) 'Environmental performance of energy systems of residential buildings: Toward sustainable communities', Sustainable Cities and Society. Elsevier Ltd, 20, pp. 96-108. doi: 10.1016/j.scs.2015.10.006.

Awan, F. (2007) Young People, Identity and the Media. Bournemounth University. doi: 10.1111/j.1600-0447.1979.tb08957.x.

De Botton, A. (2006) The Architecture of Happiness. New York: Penguin Books.

Butler-Kisber, L. and Poldma, T. (2010) 'The power of visual approaches in qualitative inquiry: The use of collage making and concept mapping in experiential research', Journal of Research Practice, 6(2). Available at: http://jrp.icaap.org/index.php/jrp/article/view/197/196.

Cieraad, I. ed. (2006) At home: an anthropology of domestic space. Syracuse University Press.

Cooper, C. (1974) The House as Symbol of the Self. Berkeley: Dowden, Hutchinson \& Ross.

Corbin, J. and Strauss, A. (2008) 'Bringing Process into the Analysis', in Basics of 
Qualitative Research (3rd ed.): Techniques and Procedures of Developing Grounded Theory. 3rd edn. Thousand Oaks: SAGE Publications, Inc., pp. 247-263. doi: http://dx.doi.org/10.4135/9781452230153.n11.

Corrigan-Doyle, E., Escobar-Tello, C. and Lo, K. P. Y. (2016a) 'Exploring Design for Happiness in the Home and Implications for Future Domestic Living', in 2016 Design Research Society 50th Anniversary Conference. Brighton: University of Brighton, pp. $1-26$.

Corrigan-Doyle, E., Escobar-Tello, C. and Lo, K. P. Y. (2016b) 'Using Art Therapy Techniques to Explore Home Life Happiness', in Happiness: 2nd Global Meeting. Budapest: Interdisciplinary Press, p. in press.

Corrigan-Kavanagh, E. (2018) Exploring Art Therapy Techniques within Service Design as a Means to Greater Home Life Happiness. Loughborough University. Available at: https://dspace.lboro.ac.uk/2134/32866.

Cristoforetti, A., Gennai, F. and Rodeschini, G. (2011) 'Home sweet home: The emotional construction of places', Journal of Aging Studies. Elsevier Inc., 25(3), pp. 225-232. doi: 10.1016/j.jaging.2011.03.006.

Deacon, S. A. (2006) 'Emergent Methods in Social Research Creativity Within Qualitative Research on Families : New Ideas for Old Methods', The Qualitative Report, 4(3), pp. 95-106. doi: 10.4135/9781412984034.

Desmet, P. M. a. and Hekkert, P. (2007) 'Framework of Product Experience', International Journal of Design, 1(1), pp. 57-66. doi: 10.1162/074793602320827406.

Drake, J. E., Coleman, K. and Winner, E. (2011) 'Short-Term Mood Repair Through Art: Effects of Medium and Strategy', Art Therapy: Journal of the American Art Therapy Association, 28(1), pp. 26-30. doi: 10.1080/07421656.2011.557032.

Duncan, S. and Phillips, M. (2008) 'New families? Tradition and change in partnering and relationships.', in Park, A. et al. (eds) British Social Attitudes: the 24th Report. London: SAGE Publications Ltd.

Gauntlett, D. and Holzwarth, P. (2006) 'Creative and visual methods for exploring identities', Visual Studies, 21(1), pp. 82-91. doi: 10.1080/14725860600613261.

Gifford, R. (2007) Environmental psychology: Principles and practice. 4th edn. Colville, WA: Optimal Books. 
Gosling, S. D., Gifford, R. and McCunn, L. (2013) 'The selection, creation, and perception of interior spaces: An environmental psychology approach', in Thompson, J. A. A. and Blossom, N. (eds) The handbook of interior design. Oxford: Berg, pp. 278290.

Hanington, B. M. (2007) 'Generative Research in Design Education', in International Association of Societies of Design Research, IASDR 2007. Hong Kong, pp. 1-15. Hulkko, S. et al. (2004) 'Mobile Probes', in NordiCHI '04. Helsinki: ACM, pp. 43-51. doi: $10.1145 / 1028014.1028020$.

Ingold, T. (2011) Being Alive: Essays on Movement, Knowledge and Description, Social Anthropology. London, New York: Routlege. doi: 10.4324/9780203818336.

LEEDR (Low Effort Energy Demand Reduction) project (2014) LEEDR (Low Effort Energy Demand Reduction) project. Available at: http://leedr-project.co.uk/ (Accessed: 15 January 2015).

Liebmann, M. (2004) Art Therapy for Groups: A Handbook of Themes and Exercises. 2nd edn. Hove, New York: Routledge.

Lusebrink, V. B. and Alto, P. (2004) 'Art Therapy and the Brain: An Attempt to Understand the Underlying Processes of Art Expression in Therapy', Art Therapy: Journal of the American Art Therapy Association, 21(3), pp. 125-135.

Malchiodi, C. A. (2007) The Art Therapy Sourcebook. 2nd edn. Hove: New York: Bruner-Routledge.

Mattelmäki, T. (2006) Design Probes. Helsinki: University of Art and Design Helsinki. Available at: https://aaltodoc.aalto.fi:443/handle/123456789/11829.

McNiff, S. (2008) 'Art-Based Research', in Knowles, J. G. and Cole, A. L. (eds) Handbook of Arts in Qualitative Research. Thousand Oaks, London, Singapore, New Delhi: SAGE Publications Inc., pp. 29-40.

Norman, D. A. (2004) Emotional Design: Why we love (or hate) everyday things. New York: Basic Books.

Peterson, C. and Seligman, M. E. P. (2004) Character Strengths and Virtues: A Handbook and Classification. Oxford, New York: Oxford University Press. Pink, S., Leder Mackley, K. and Morosanu, R. (2015) 'Researching in atmospheres: 
video and the "feel" of the mundane', Visual Communication, 14(3), pp. 351-369. doi: $10.1177 / 1470357215579580$.

Rubin, J. (2001) Approaches to Art Ttherapy. New York: Brunner/Mazel.

Rubin, J. (2011) The Art of Art Therapy: What Every Art Therapist Needs to Know. New York, East Sussex: Routledge.

Sanders, E. B. N. (2001) 'Collective creativity', LOOP: AIGA Journal of Interaction Design Education, 6(3), pp. 1-6. Available at: http://www.maketools.com/articlespapers/CollectiveCreativity_Sanders_01.pdf\%5Cnhttp://scholar.google.com/scholar?hl $=$ en $\& b \operatorname{tnG}=$ Search $\& \mathrm{q}=$ intitle:Collective + Creativity $\# 6$.

Sanders, E. B. N. (2006) 'Scaffolds for building everyday creativity', Designing effective communications: creating contexts for clarity and meaning, pp. 65-77. Sanders, E. B. N. and Stappers, P. J. (2012) Convivial Toolbox: Generative Research for the Front End of Design. London: BIS Publishers.

Sanders, E. B. N. and Stappers, P. J. (2014) 'Probes, toolkits and prototypes: three approaches to making in codesigning', Codesign: International Journal of Cocreation in Design and the Arts. Taylor \& Francis, pp. 5-14. doi:

$10.1080 / 15710882.2014 .888183$.

Seligman, M. E. P. (2002) Authentic Happiness. New York: Atria Paperback.

Silverstone, L. (2009) Art Therapy Exercises: Inspirational and Practical Ideas to Stimulate the Imagination. London: Jessica Kingsley Publishers.

Springham, N. (2008) 'Through the eyes of the law: What is it about art that can harm people?', International Journal of Art Therapy, 13(2), pp. 65-73. doi: 10.1080/17454830802489141.

Visser, F. S. et al. (2005) 'Contextmapping: experiences from practice', CoDesign, 1(2), pp. 119-149. doi: 10.1080/15710880500135987. 


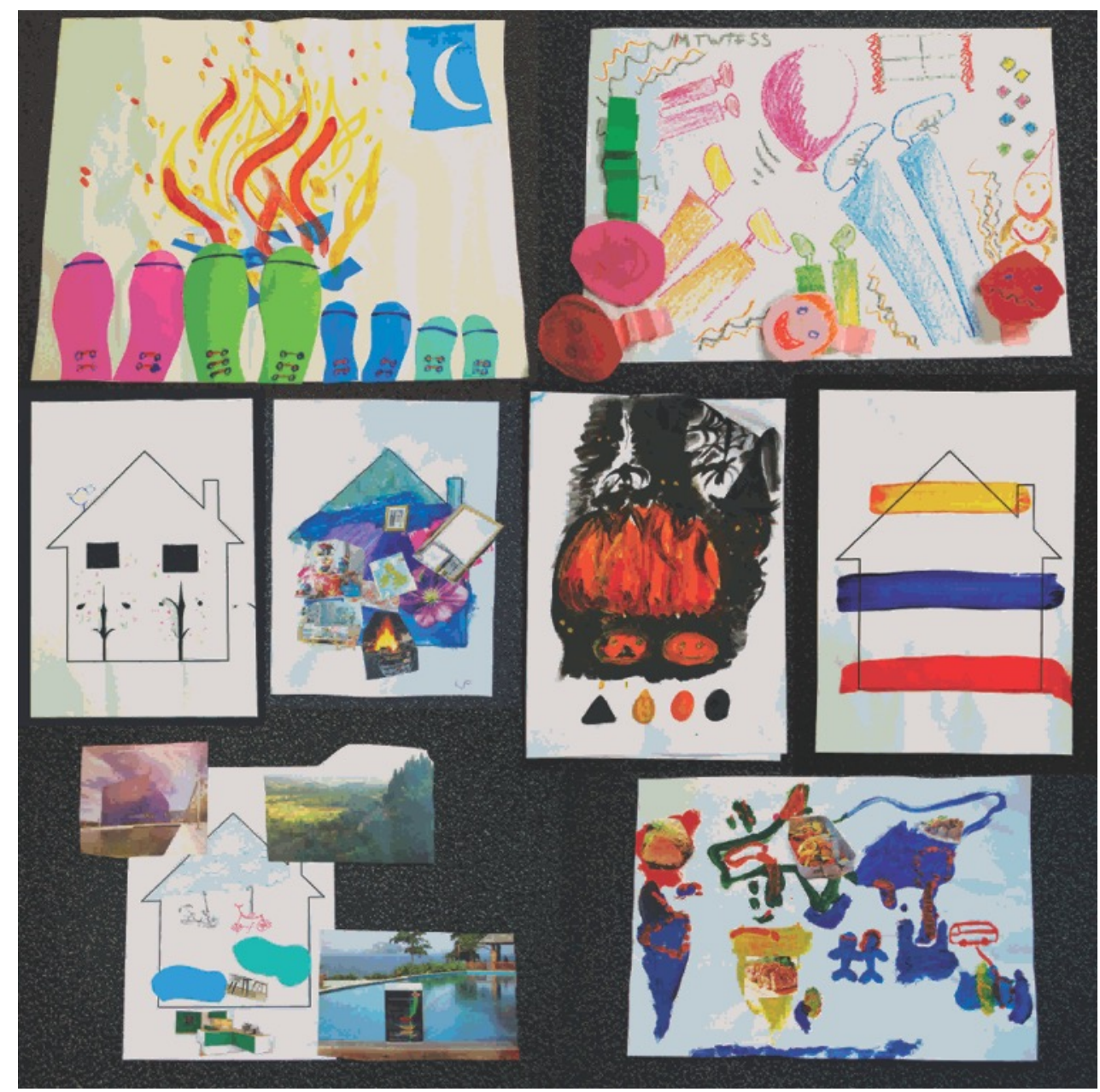

Figure 1. A sample of artwork resulting from studies using art therapy techniques. Used with permission. 


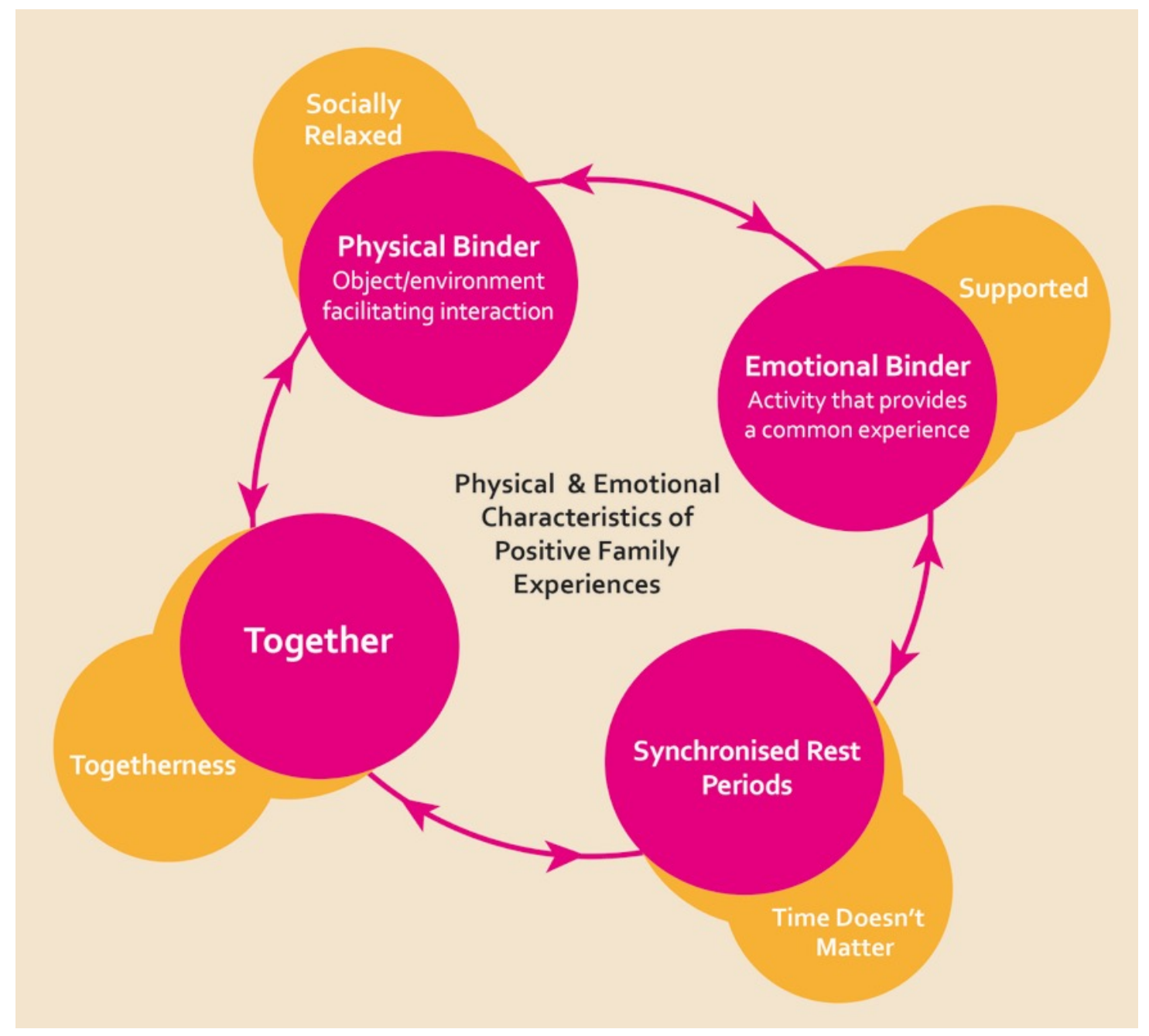

Figure 2. A general depiction of which physically enacted characteristics of positive family experiences lead to specific emotionally felt qualities and how these collate into pleasant family occasions. Original work by authors. 


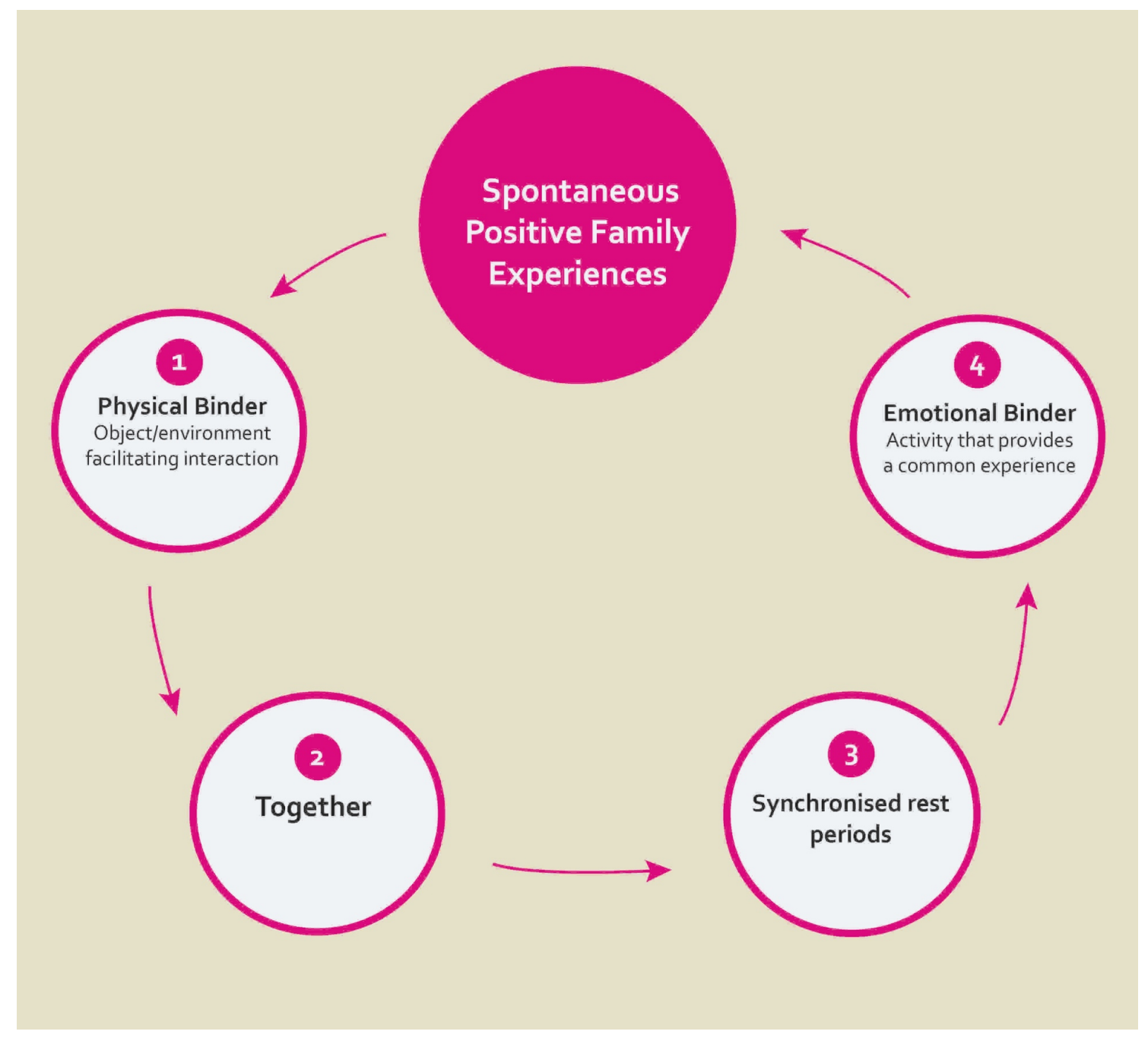

Figure 3. The sequence in which physically enacted characteristics occur during spontaneous positive family experiences. Original work by authors. 


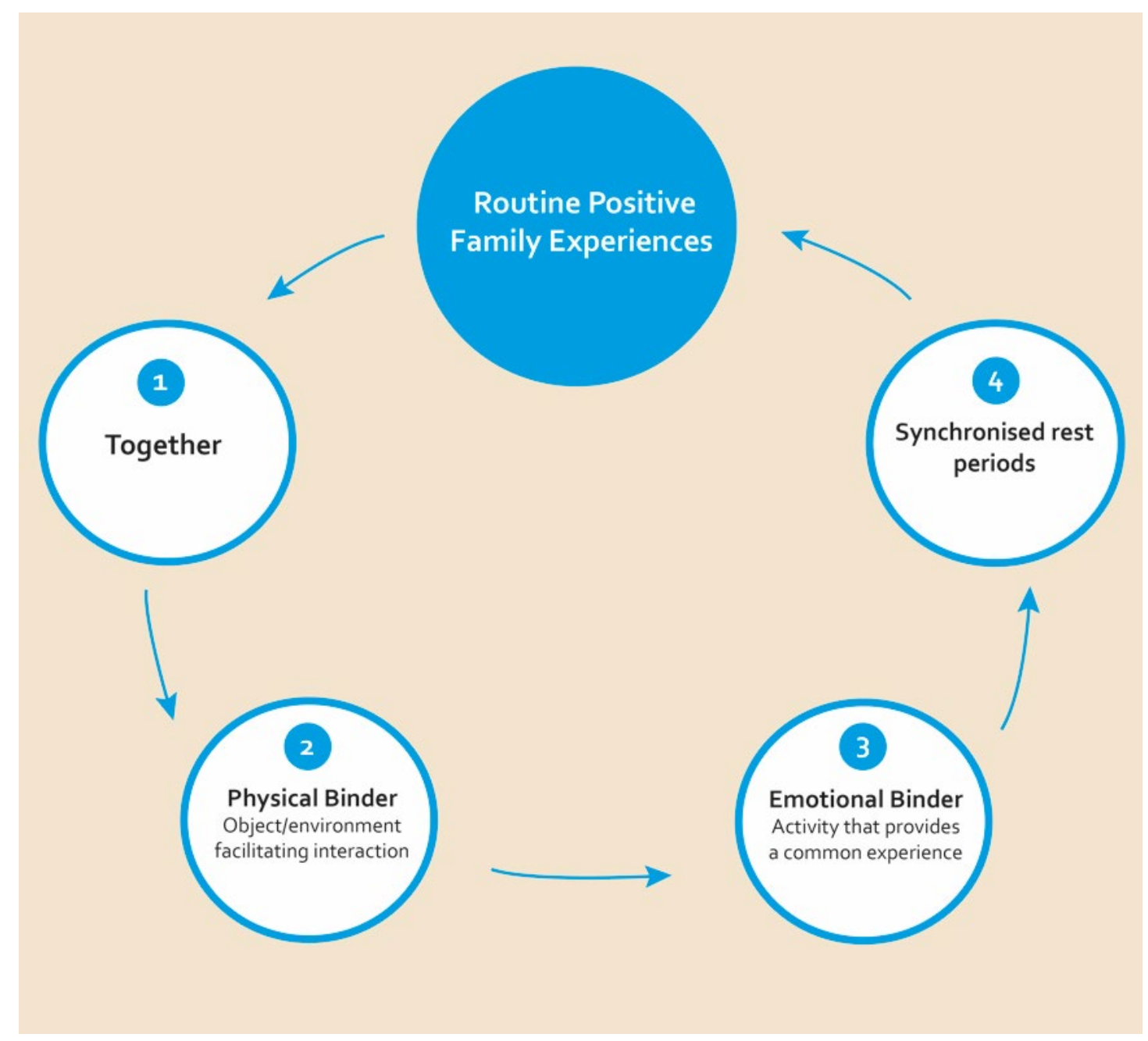

Figure 4 . The sequence in which physically enacted characteristics occur during routine positive family experiences. Original work by authors. 


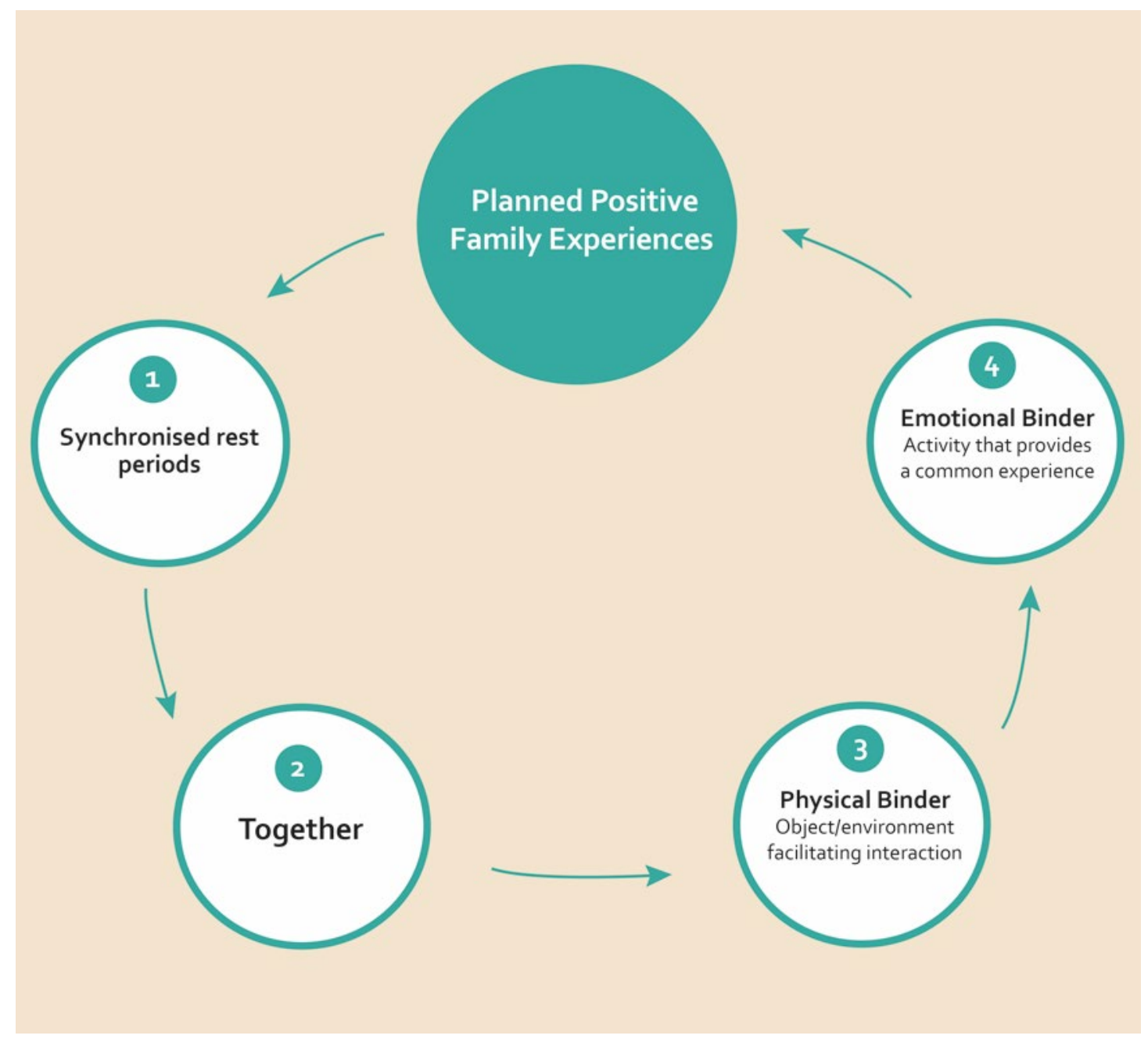

Figure 5. The sequence in which physically enacted characteristics occur during planned positive family experiences. Original work by authors.

Table 1. Tasks, procedures and art therapy techniques employed in Happy-Homes Workshops.

\begin{tabular}{|l|l|l|}
\hline \multicolumn{1}{|c|}{ Activities } & \multicolumn{1}{|c|}{ Procedure } & \multicolumn{1}{c|}{ Art Therapy Techniques } \\
\hline & $\begin{array}{l}\text { Workshop preparation. } \\
\text { I. Participants to reflect (notes } \\
\text { and/or drawings) on their previous } \\
\text { experiences and perceptions of art, } \\
\text { and about personal home spaces } \\
\text { prior to workshop. }\end{array}$ & $\begin{array}{l}\text { I. Personal art history, image } \\
\text { awareness (Malchiodi, 2007). }\end{array}$ \\
$\begin{array}{l}\text { Activity I. } \\
\text { Art Halking of Persong individually in a group } \\
\text { Image Awareness } \\
\text { Exercise Results }\end{array}$ & $\begin{array}{l}\text { (ibid). } \\
\text { 2. Participants to introduce selves } \\
\text { and share reflections with the group } \\
\text { (max. 20 mins). }\end{array}$ & \\
\hline
\end{tabular}




\begin{tabular}{|c|c|c|}
\hline $\begin{array}{l}\text { Activity } 2 . \\
\text { Spontaneous Art } \\
\text { Making Exercise }\end{array}$ & $\begin{array}{l}\text { I. Facilitator to provide participants } \\
\text { with a diverse range of art supplies } \\
\text { (i.e. painting supplies, crayons, } \\
\text { markers, colouring pencils, paper of } \\
\text { different sizes and colours) and a } \\
\text { page each with a black outline of a } \\
\text { house. } \\
\text { 2. Participant to decorate this page } \\
\text { using any of the materials available, } \\
\text { without speaking (max. } 10 \text { mins). } \\
\text { 3. Participants to individually explain } \\
\text { their image to the group once time } \\
\text { for the previous task elapses (max. } \\
\text { 15 mins). }\end{array}$ & $\begin{array}{l}\text { I. Creative freedom (Rubin, 20I I). } \\
\text { 2. Free association (Malchiodi, 2007), } \\
\text { spontaneous art-making (Rubin, } \\
\text { 20II), silent art- making (Rubin, } \\
\text { 2009). } \\
\text { 3. Individually talking in a group } \\
\text { (Malchiodi, 2007), limited outsider } \\
\text { interpretation of artwork (Curtis, } \\
\text { 20II). }\end{array}$ \\
\hline $\begin{array}{l}\text { Activity } 3 . \\
\text { Visualising Positive } \\
\text { Family Time } \\
\text { Exercise }\end{array}$ & $\begin{array}{l}\text { 1. Participants to visualise a positive } \\
\text { family experience using any of the } \\
\text { materials provided, without } \\
\text { speaking (max. } 30 \text { mins). } \\
\text { 2. Participants to discuss the } \\
\text { meaning of their images with the } \\
\text { group without interpretations or } \\
\text { interruptions from others (max. } 30 \\
\text { mins). }\end{array}$ & $\begin{array}{l}\text { I. Silent art making, creative } \\
\text { freedom. } \\
\text { 2. Individually talking in a group, } \\
\text { limited outsider interpretation of } \\
\text { artwork. }\end{array}$ \\
\hline
\end{tabular}

Table 2. The full list of themes, their codes and sample related data extracts emerging from the Happy-Homes Workshops.

\begin{tabular}{|c|l|l|}
\hline Themes & \multicolumn{1}{|c|}{ Codes } & \multicolumn{1}{c|}{ Data Extracts } \\
\hline \multirow{4}{*}{ Emotionally felt } & Togetherness & $\begin{array}{l}\text { 'I think the enhancing [of the } \\
\text { moment] is just the physical being } \\
\text { there and being together' }\end{array}$ \\
\cline { 2 - 3 } & Time doesn't matter & $\begin{array}{l}\text { 'I remember there was lots of lying } \\
\text { around' }\end{array}$ \\
\cline { 2 - 3 } & Socially relaxed & $\begin{array}{l}\text { '...he sometimes lets me stroke his } \\
\text { hair for a very small moment' }\end{array}$ \\
\cline { 2 - 3 } & Supported & $\begin{array}{l}\text { 'The snuggling up is nice...You're } \\
\text { doing it for the [other] people' }\end{array}$ \\
\hline
\end{tabular}




\begin{tabular}{|l|l|l|}
\hline \multirow{4}{*}{$\begin{array}{l}\text { Physically } \\
\text { Enacted }\end{array}$} & $\begin{array}{l}\text { Synchronised Rest Periods (i.e. } \\
\text { making time for each other either } \\
\text { consciously or unconsciously) }\end{array}$ & $\begin{array}{l}\text { '...last Christmas, we had two } \\
\text { weeks when all of us were home' }\end{array}$ \\
\cline { 2 - 3 } & Group activities & $\begin{array}{l}\text { '...it was the only movie that we } \\
\text { would have sat down and watched } \\
\text { together' }\end{array}$ \\
\cline { 2 - 3 } & Together & '...the physically being there' \\
\cline { 2 - 3 } & $\begin{array}{l}\text { Objects or contexts facilitating } \\
\text { collective interaction }\end{array}$ & 'Me and my son were on the sofa' \\
\hline
\end{tabular}

Table 3. Overview of key findings from Happy-Home Workshops and follow-up semistructured interviews.

\begin{tabular}{|c|c|c|c|c|}
\hline $\begin{array}{l}\text { Positive family } \\
\text { Experience } \\
\text { type to support }\end{array}$ & \multicolumn{4}{|l|}{ Spontaneous } \\
\hline $\begin{array}{l}\text { Physically } \\
\text { enacted } \\
\text { characteristics } \\
\text { in order of } \\
\text { occurrence }\end{array}$ & I. Physical binder & 2. Together & $\begin{array}{l}\text { 3. Synchronised } \\
\text { rest periods }\end{array}$ & $\begin{array}{l}\text { 4. Emotional binder } \\
\text { (for pleasure, } \\
\text { engagement and } \\
\text { meaning) }\end{array}$ \\
\hline Description & $\begin{array}{l}\text { An object and/or } \\
\text { context that facilitates } \\
\text { a positive family } \\
\text { interaction/emotional } \\
\text { binder and enables } \\
\text { family members to } \\
\text { feel 'socially relaxed'. }\end{array}$ & $\begin{array}{l}\text { The family is } \\
\text { physically } \\
\text { together, and } \\
\text { this enables } \\
\text { feelings of } \\
\text { 'togetherness'. }\end{array}$ & $\begin{array}{l}\text { The family } \\
\text { consciously or } \\
\text { unconsciously } \\
\text { make time for } \\
\text { each other and } \\
\text { spend a } \\
\text { prolonged } \\
\text { period together. } \\
\text { This creates the } \\
\text { feeling that } \\
\text { 'time doesn't } \\
\text { matter' }\end{array}$ & $\begin{array}{l}\text { An inclusive activity } \\
\text { that occurs during a } \\
\text { positive family } \\
\text { experience, } \\
\text { supported by } \\
\text { physical binder(s) } \\
\text { and facilitates } \\
\text { feeling 'supported'. }\end{array}$ \\
\hline
\end{tabular}




\begin{tabular}{|l|l|l|l|l|}
\hline $\begin{array}{l}\text { Emotionally felt } \\
\text { characteristics } \\
\text { in order of } \\
\text { occurrence }\end{array}$ & I. Socially relaxed & 2. Togetherness & $\begin{array}{l}\text { 3. Time doesn't } \\
\text { matter }\end{array}$ & $\begin{array}{l}\text { 4. Supported } \\
\text { (mentally and } \\
\text { physically) }\end{array}$ \\
\hline & $\begin{array}{l}\text { Feeling socially } \\
\text { relaxed from the } \\
\text { presence of 'physical } \\
\text { binders' (e.g. } \\
\text { comfortable seating). }\end{array}$ & $\begin{array}{l}\text { Feeling a sense } \\
\text { of togetherness } \\
\text { by being } \\
\text { physically } \\
\text { 'together' with } \\
\text { family. }\end{array}$ & $\begin{array}{l}\text { Feeling as } \\
\text { though time } \\
\text { doesn't matter } \\
\text { because family } \\
\text { members have } \\
\text { 'synchronised } \\
\text { rest periods'. }\end{array}$ & $\begin{array}{l}\text { Feeling supported } \\
\text { by engaging in } \\
\text { 'emotional binders' } \\
\text { (e.g. talking and } \\
\text { resting). }\end{array}$ \\
\hline
\end{tabular}

